\title{
Policies and Practices of Mainstreaming Gender Equality and Women Empowerment in Higher Educational Institutions: The Case of Dilla University, Ethiopia
}

\author{
Daniel Amente \\ PhD Candidate in Public Management and Policy, Addis Ababa University, Ethiopia
}

\begin{abstract}
The main purpose of this study was to find out whether Dilla University (DU) has mainstreamed gender into its systems to contribute towards the attainment of gender equality and women empowerment. It was, therefore, the objective of the research to assess and analyze the policies, programmes, and practices of the University in order to examine the extent to which gender issues are integrated as part and parcel of the overall system. It was also important to evaluate the gender-related perceptions and attitudes of the members of the academic community to determine the orientation of key players in the University with regards to gender perspectives and the implementation of policies and programs. The research is also aimed at identifying areas of achievements in the University towards gender equality. At the same time, this research also aspired to identify gaps in mainstreaming gender by analyzing both qualitative and quantitative data acquired through different means. To this end, a significant number of policy and legislative documents were reviewed. High level officials of the University and representatives of special interest groups were interviewed, using semi-structured questions. Attitude survey was also conducted on 636 randomly selected academic staff and students who responded to predesigned questionnaires. For the sake of validity and reliability, the data analysis was triangulated using qualitative and quantitative analytical tools. The findings show that, in spite of some commendable but limited efforts, the University lacks the level of commitment, understanding, capacity and operational as well as institutional framework which is necessary for proper gender mainstreaming. In addition, gender inequality was not seen as a major factor underpinning the policies and strategies of the University. There is the huge gender disparity across most of the human resource dimensions, particularly among students and academic staff. In addition, the research also revealed the qualitative inequality aspects of gender. The data acquired from the research participants implies that the attitude and perceptions of the University community members are a replica of the Ethiopian society at large though progress are being made. Based on these findings, the research has concluded that DU has not yet sufficiently mainstreamed gender to contribute towards gender equality and the empowerment of women. To create gender-equitable academic environment, the University management should lead by example by showing commitment to gender mainstreaming, treat gender equality as a cross-cutting as well as a specific goal, build on the modest foundation and strengthen Gender Office's infrastructure in terms of resource and conduct continuous awareness creation sessions in collaboration with the Gender Office. Moreover, the Gender Office of the University should utilize an effective advocacy approach and expand strategic partnerships with the stakeholders.
\end{abstract}

Keywords: Gender, gender equality, women empowerment, gender mainstreaming

DOI: $10.7176 / \mathrm{JEP} / 10-34-05$

Publication date: December $31^{\text {st }} 2019$

\section{Introduction}

\subsection{Background of the Research}

The debate on gender and development has grown enormously in the last forty years and has emerged as an academic discipline, as a job position and work unit in organizations, and as a training program in institutions. Despite the vast quantity of literatures and academic materials published on the positive relationship between gender equality and development, 'gender' as a concept remains elusive, misunderstood, and politicized across the spectrum of society.

Gender can be defined as a set of characteristics, roles, and behavioral patterns that distinguish women from men socially and culturally and mediate the relations of power and labor between them (Women Information Centre, 2005). These characteristics, roles, behavioral patterns and power relations are dynamic; they vary over time and between different cultural groups because of the constant shifting and variation of culture and subjective meanings of gender (Hirut, 2014). The difference in power relations between men and women results in different gender and social roles as well as socially assumed appropriate characteristics and behaviors. All are culture-specific and can change; thus gender is a policy concern of justice and equality.

For Kabeer (2003), gender equality means both equality of treatment under the law and equality of opportunity in the socio-economy and polity. However, she cautions that such definitions usually do not take structural inequality into account, but rather include substantive equality and that of agency. Kabeer (2003:19) 
describes substantive equality as suggesting that "the different circumstances and characteristics of men and women have to be considered to avoid unfair gender-related outcomes"; while equality of agency means "ensuring that both women and men can make strategic life choices for themselves and help determine the conditions under which these choices are made". Thus, gender equality requires adapting equally to the needs and interests of girls and boys and creating an environment that is friendly to both sexes and ensuring that women are equally represented in teaching, administrative \& educational leadership roles including in Higher Educational Institutions (HEIs).

The process of correcting gender disparity in a society leads us to improving the condition and status of women in all spheres (household as well as community level) which is also termed as women empowerment. Bezawit and Singh (2019) define empowerment as a process by which those who have been denied the ability to make choices acquire such ability. In the gender equation, empowerment is required for women since they are the ones who have generally been deprived of opportunities to make choices in their lives.

Increase in education has often been cited as one of the major avenues through which women are empowered. Improving women's access to education, with the goal of attaining gender equality, is a critical component of promoting development and meeting the Sustainable Development Goals (SDGs) in Ethiopia. Educating women is essential to economic development and poverty reduction. World Bank research (2011) shows that countries with smaller gaps between women and men in areas such as education, employment and property rights not only have lower child malnutrition and mortality but also more transparent business and government and faster economic growth, which in turn helps to further narrow the gender gap. In order for new knowledge societies not to recreate and reinforce systemic social inequalities, gender mainstreaming in HEIs is important.

Gender gap in access to education is more pronounced at secondary and higher education levels. According to UN (2013), in most developing countries, gender disparities in access to education increase with increasing level of education. Among 65 developing countries for which the required data were available, about half have achieved gender parity in primary education, $20 \%$ of them achieved gender parity in secondary education, and only $8 \%$ of them in higher education (UNFPA, 2008). Surprisingly only two out of 130 countries with available data have achieved the target of gender parity at all levels of education (UN, 2013).

As Barbour (1997) stated, females learning in higher educational institution is greatly affected by the attitudes, values and actions emanates from home, school, and communities in addition to the conduciveness of the policy environment in the institutions. He also emphasized that management commitment and orientation is important in mainstreaming gender issues in different operations of institutions. Moreover, according to MoE (2013) the goal to produce highly qualified, motivated and innovative human resource and transfer of advanced and relevant knowledge for socio-economic development and poverty reduction with a view to turning people of the country into middle-income society is impossible without targeting both men and women equally in higher education. Therefore, the research was aimed at assessing the policies and practices of gender mainstreaming for gender equality and women empowerment in higher educational institutions particularly in the case of DU.

\subsection{Problem Statement}

It is now more than half a century since the negative impact of women's exclusions from or under-representation in different spheres of life has begun to be well recognized and documented at global level. Ever since, promoting gender equality through women's empowerment has become a major strategy to achieve human development, poverty eradication and economic growth. This has come through efforts exerted not only by women but also by men as well that have concerns about the historical status of women in society.

A number of studies have shown that sustainable development is impossible without women's empowerment by ensuring gender equality. Consequently, it is asserted that gender equality is both human rights and policy issue and a precondition for, and indicator of, sustainable development (Alvarez and Lopez, 2013). It is also affirmed that gender disparity is prevalent across the cultures of the world and that without serious steps to tackle it, sustainable development cannot be achieved (Stevens, 2010). Furthermore, UN Women (2014) rightly outlined that to create a just and sustainable world and to enhance women's roles in sustaining their families and communities, achieving gender equality is paramount. On the other hand, if gender equality is not maintained, it will retard the country's development. In line with this idea, Stevens (2010:44) interestingly underlines that "an increasing number of studies indicate that gender inequalities are extracting high economic costs and leading to social inequities around the world."

Therefore, one can understand from such explanations that without the equal inclusion of women in all areas of development initiatives, sustainable development cannot be achieved. However, gender inequalities across economic, social and political dimensions remain widespread and persistent (UN Women, 2014). Ethiopia's case is also very much apparent. Being cognizant of the negative effects of the prevailing gender disparity, the Ministry of Education (2015:5) affirmed that "any development initiative has to engage and ensure that both men and women contribute and benefit equally from it." 
Despite some economic progress over the last decade, Ethiopia remains one of the poorest countries in the world in terms of several economic parameters. Further to sharing the burden of poverty with their male counterparts, women in Ethiopia are subjected to gender based discrimination, most notably in rural areas (MoFED \& UNCT, 2014). The Ethiopian government acknowledges that "promoting gender equality for Ethiopia", where women constitute approximately half of the populace, "is not only in the best interest of the society at large, but also fundamentally that of ensuring the human and democratic rights of women" (ESDP IV, 2013:18). In other words, the condition of the Ethiopian economy is significantly one of subsistence partly because women are less literate, discriminated in productive activities, engaged in invisible labor services that are not taken into account in the national gross domestic product (GDP) statistics, and are paid less for the same work in the informal market. To address gender issues in Ethiopia therefore not only concerns equity and social justice, but also development and poverty reduction (WAO, 2014). In this respect, education which is viewed as human capital formation is one of the most important factors in marching towards gender equality.

Though women in the country have constitutional rights of participation in decision making, their involvement is limited at all levels. For instance, the report of the National Electoral Board of Ethiopia indicates that, among 547 seats of the Federal Parliament, only $29 \%$ of them were occupied by women. At regional and district levels, women constitute only $13 \%$ and $14 \%$ of council members and elected officials, respectively (Federal Civil Service Commission, 2010). It is also the case that women have little or no power to make decisions on matters related to their own households. Their decision making power is limited regarding land use in rural areas (Haregewoin and Emebet, 2013) and even on sexual interactions (Adanech and Azeb, 2009). Mostly women in the country have the power to make decisions on issues related to the daily life of their family, but decisions about large household purchases, degree of participation of a woman in social activities, and reproductive health issues are dominated by men.

Due to the prominence that gender issues have gained over the last few decades, many institutions including DU have been engaged in some form of gender related projects. Unfortunately, most of these projects are standalone undertakings focused on addressing isolated issues in an ad-hoc manner. The main argument of this research is that the goal of gender equality and women empowerment is difficult to achieve without mainstreaming gender issues in the existing and planned policies and practices of an institution. Gender equality requires adapting equally to the needs and interests of girls and boys and creating an environment that is friendly to both sexes and ensuring that women are equally represented in teaching, administrative and educational leadership roles in HEIs. Moreover, HEIs are expected to avail gendered academic environment to obtain decent employment and participate equally in decision-making in the political, economic and social areas. Unfortunately, the overall enrolment rate of the higher education in Ethiopia is very low with a gross enrolment ratio (GER) of $4.6 \%$ (the female GER is $2.2 \%$, that of male students is $7.0 \%$ ) (MoE, 2009:59). There were 50,643 graduates in 2007/08 of which 20\% were female (MoE, 2009). Out of the total teaching staff in 2007/08, only $8.4 \%$ and $14 \%$ were women in government and private institutions respectively (MoE 2012:10; MoE 2009:125-126). Of course, women's low involvement in higher learning in Ethiopia is the reflection of the low enrolment and academic performance of girls in primary and secondary education (MoE, 2012). The situation is even worse in DU where female academic staffs constitute only $7.4 \%$ of the total teaching staff. Moreover, out of the 4,423 graduates from DU in 2012/13 academic year, the share of female graduate is only $17 \%$ which is quite below the national average of $29.7 \%$. In addition, the gender parity index (GPI) at enrollment was 0.78 in 2008/09 academic year in DU however it continuously declined in the coming years to be 0.29 in $2012 / 13$ academic year. The GPI differential which measures the success rate of male and female students also indicates that female students in DU had relatively low success rate as compared with their male counterparts in the past five years.

In addition to the glaring quantitative imbalances, female students in the University are subjected to subtle environmental challenges such as inconvenient sanitary facilities, verbal abuse and sexual harassment that make their academic and social life more difficult. It is therefore important to empower women and ensure gender equality at the University level with a purposeful and critical review of all the variables affecting women's productivity.

A group of scholars from Norway (Soyland, et al., 2000) concluded that "perhaps the inadequacy of the efforts to achieve gender equality is not the main problem; rather, the understanding, wish, and will to change constitute the real challenge". Thus, in order to contribute towards the national goal of gender equality and women empowerment, DU community need to possess the understanding, will and resources to change and mainstream gender in all aspects of the work of the University.

USAID-IQPEP (2012) made an attempt to explore policy-practice gaps of female leadership in the Ethiopian education system. The research concludes that the extent of implementation of the policy provisions with respect to encouraging females both at regional and wereda levels seems to be less gravitating towards standardization; thus, demonstrating disparity in the levels of implementation. Moreover, it finds out that females are confronted with multi-faceted challenges which hinder them from assuming and sustaining leadership 
positions. Although such attempts are made, there is no specific research output which thoroughly targeted at assessing the policies, programmes and practices of mainstreaming gender equality and women empowerment in HEIs particularly in DU. Therefore, this research mainly aims at investigating the problems associated with policy implementation, the conduciveness of policy environment in the institution as well as identifying gaps in integrating gender issues in the operations of the University since an institution is not believed to contribute effectively to the national development effort without mandating the integration of gender into its operations.

\subsection{Research Objective}

The main objective of the study is to analyze the gender mainstreaming at DU in terms of gender equality and empowerment policy and implementation. The specific objectives are to:

- Assess the conduciveness of policy environment to gender equality in the University

- Analyze the gender-related perceptions and attitudes of the members of the academic community

- Explore the achievements gained towards gender equality and empowerment of women in the University

- Identify gaps in integrating gender issues in the programs of the University

- Provide an entry options for gender equality on the basis of identified good practices and areas of improvement.

\section{Review of Related Literature}

\subsection{Gender Equality and Women Empowerment: Historical and Theoretical Perspectives}

The ongoing struggle for equality can be traced to many decades of hard work by women's rights advocates, humanitarian organizations, and development agencies. "The manner in which development actors have perceived and addressed the role of women in the development process has undergone a series of significant conceptual and operational shifts over the last 50 years" (UNDP, 2013).

Women's involvement in development during the post $2^{\text {nd }}$ World War era until the 1970 s was characterized by what is known as a 'welfare approach' (UNDP, 2003 citing Moser, 1993). This approach perceived women as passive beneficiaries of aid instead of agents for development, focused on their reproductive responsibilities and ignored their productive roles (UNDP, 2003). Brett (1991) also chronicled that in the 1950s and 1960s, some elements of women's issues in development were considered under the questions of human rights although women were not necessarily consulted in the process. Use of a limited amount of data to emphasize the differential impact of development on women and men was pioneered by Ester Boserup in the 1970s (LeoRhynie, 1999; UNDP, 2003). Women's rights advocates stepped up their involvement by reacting to such initiatives and initiated a call for legal and administrative reforms to incorporate women's concerns into economic policies and practices (Brett, 1991; Leo-Rhynie, 1999). These movements led to what is called the 'Women in Development' (WID) approach.

The WID movement explicitly called for social justice and political equality for women, improved education and employment opportunities, and increased health and welfare services (Razavi \& Miller, 1995). The WID movement introduced legislation to protect women's rights, most notably the CEDAW in 1979. CEDAW is the most important international agreement which triggered many organizations to undertake advocacy, lobbying, research, and outreach activities that have pushed governments and organizations to be more responsive to women's needs (Neuhold, 2005; UNDP, 2003). WID also takes credit for the national women's machineries and WID units within development agencies that flourished in many countries during the 1990s (UNDP, 2003).

Notwithstanding its significant contributions, with the passage of time, the WID approach was criticized for being ineffective in terms of fostering improvement in women's lives (Leo-Rhynie, 1999). In fact, according to Leo-Rhynie (1999), although the world had experienced over two decades of modernization, the position of women actually declined in some sectors. As the UNDP (2003) reported, "in many cases, the very act of separating women's programming from the central, mainstream programming which involved men, resulted in increased marginalization of women and their roles - precisely the opposite effect from that which was intended". Razavi and Miller (1995) also agree that while WID was successful as a political strategy by way of giving women some level of visibility, it was also to blame for women's demands being sidelined from the main development agenda.

In an effort to address the gaps arising from the WID approach, a new approach, Gender and Development (GAD), began to feature in the early 1990s by advocating for gender mainstreaming (UNDP, 2003). The different gender approaches that GAD embodies share a focus on the analysis of the different roles of men and women and their respective access to and control over resources and decision-making (UNDP, 2003). Two of the main GAD approaches are: the 'gender roles' framework developed by the Harvard Institute for International Development and USAID; and the 'social relations analysis', which is associated with the work of the Institute for Development Studies at Sussex (UNDP, 2003). The UNDP (2003) defines the two approaches as follows: 
The gender roles framework focuses on the household unit as a system for allocating resources among its members -rather than as a cohesive, cooperative group that shares a common production and consumption system. It emphasizes women's individual access to and control over resources within the family and their productive contributions to the household, which provide the rationale for allocating resources to them. As in WID, the justification for directing resources to women is economic efficiency. Efficiency has "enormous rhetorical appeal" and, because it focuses on redistributing discrete economic inputs, the gender roles framework sidesteps the potentially controversial and threatening issue of redistributing power. Social relations analysis, on the other hand, addresses the issue of power head-on. Indeed, empowerment strategies are its logical outgrowth. The central problem here is not the lack of women's integration in development, but rather, the social structures, processes, and relations that give rise to women's disadvantaged position in a given society. As such, ending women's subordination is viewed as more than a matter of reallocating economic resources. It involves redistributing power. Proponents of social relations analysis recognize that the redistributive process is a zero sum game... and men will have to relinquish some of the economic, political and social power. Social relations analysis looks not just at gender, but also at other forms of social differentiation - class, ethnicity, race, age, and caste. This approach is more threatening as it challenges the status quo in a fundamental way.

Although GAD is a significant step forward and is adopted by many development agencies (Cornwall, Harrison \& Whitehead, 2004), experts still argue that it falls short of being a transformative approach that uproots gender inequality and treats it as a violation of human rights. GAD, rather, focuses more on the economic aspect of gender equality and compels governments and organizations to integrate gender into the existing policies and strategies in a gradual and systematic fashion. Scholars are already challenging the notion that the desired outcome is unlikely to be attained unless the world deals with mainstreaming the fundamental issue - addressing gender and development within a human rights framework (UNDP, 2003). The main challenges that the transformative approach faces are the lack of gender mainstreaming capacity, ineffective organization structure (Fukuda-Parr, Lopez \& Malik, 2002), a lack of conceptual clarity and of management commitment, unmatched by adequate resource allocation to implement a gender mainstreaming strategy (UNDP, 2003; Mukhopadhyay, 2004).

The 1995 Fourth Women's Conference which is also known as the Beijing Platform for Action (BPFA) made a landmark contribution in terms of setting a global policy framework to advance gender equality and concretize some of the goals of CEDAW (Molyneux \& Razavi, 2005; Mukhopadhyay, 2004; Neuhold, 2005). The UN has been spearheading the movement in setting standards for gender equality and women's rights over the last number of years. However, the UN was criticized for not leading by example, such as installing a strong, independent operational agency that could authoritatively marshal the international effort towards gender equality and empowerment of women (Turquet, Watt \& Sharman, 2007). On 7 July 2010 the UN SecretaryGeneral, Ban Ki-Moon, dispatched a letter to all UN agencies heralding the UN General Assembly's unanimous adoption of a resolution on system-wide coherence, which includes the creation of the United Nations entity for gender equality and the empowerment of women, to be known as UN Women. The Secretary-General expressed his hope that "UN Women will significantly boost UN efforts to promote gender equality, expand opportunity, and tackle discrimination around the globe". The agency is headed by an Under-Secretary-General and is given a clear and strong mandate to coordinate, conduct research, and support member states on gender related matters.

Since its introduction, MDG-3 is spearheading the global effort towards gender equality. MDG-3 garners WID, which championed women empowerment, and GAD which propagated gender equality through mainstreaming. As a result, gender equality is perceived as not only a goal in its own right but also a means to achieve other MDGs.

\subsection{Gender Perspectives in Education}

Leo-Rhynie (1999:18) has contributed to the dimensions of looking at gender perspective in education. She quoted Measor and Skies (1992) who identified three feminist perspectives on gender and education: the liberal, socialist and radical perspectives.

The liberal view is that education replaces ignorance and prejudice with knowledge and enlightenment. The major concern is with girls and women being allowed equal access to education, and the legal frameworks ensuring equity of access and equal opportunity in educational settings. The socialist perspective involves a commitment to social change with the objective of eliminating social class inequity as well as gender inequity. From this perspective, schools are seen as reproducing the status quo. The agenda here is primarily concerned with the ways in which education reinforces inequity, and methods which need to be implemented to resist or change this. The radical perspective works towards reforming the power relationships between girls and boys in the classroom, where it is assumed that boys dominate the classroom, to the girls' detriment. Similarly, the curriculum, in this view, is geared toward boys' interests, and teachers are found to favor boys over girls. Sexual harassment of girls by male students and teachers is another concern.

The shortcoming of these three perspectives is that they tend to ignore the demand and supply factors 
affecting the education environment. The approach appears to have focused on what happens once the students are within the school environment. What is equally important, especially if the plan is to bring about faster and sustainable gender equity, is to link the study with the demand side that is affected by socio-economic and cultural factors and the supply side, which is shaped by political and institutional factors linked to the school.

Authors, such as Blackden et al. (2006), suggested that specific incentives such as abolishing tuition fees for primary education and introducing special programmes to target female education could contribute to attracting more female students. However, Meena (2007), who cited a study conducted for the Forum for African Women Educationalists (FAWE), blamed the "inconsistencies and discrepancies between the policy commitments on the one hand and the plans and strategies for redressing gender imbalance in the field of education on the other". Leo-Rhynie is one of the authors who comprehensively addressed the variables that could contribute towards an engendered education system. She (Leo-Rhynie, 1999) concluded that "no single perspective is able to represent the variety and breadth of issues in gender and education, but rather informed by other perspectives, these approaches can help build a comprehensive picture of the multi-dimensional education process and its role in gender inequity".

There are limits to what education can do as a means to achieve empowerment and gender equality (Johnson, 2005). According to Kabeer (2005), in societies characterized by extreme forms of gender inequality, even if women are afforded an opportunity to enjoy access to education, the expectations are such that they would be "a better wife, mother, and have a better chance of getting a suitable husband". Therefore, for education to have the desired impact on gender equality and, by extension, on development, both the internal environment (pedagogical) and external environment (social, economic, political) must be gender-responsive.

\subsection{Gender Equality and Higher Education}

As University Partnerships in Cooperation and Development (UPCD, 2004) stated, it is difficult to imagine the realization of the MDGs without higher education. Higher education institutions (HEIs) are recognized as a key force for modernization and development, especially in developing countries (Tefera \& Altbach, 2004). HEIs are the major means of empowerment through which both men and women could realize their potential (Grunberg, 2001). As Assie-Lumumba (2007) articulated very well higher education is one of the most important sectors of human resource formation, especially in a developing world. It is an area where philosophers, technicians, scientists, and humanists are formed and produced. In principle, with their specialized and general knowledge, skills, research and innovative capacities, these actors can be considered as the primary agents or engines of social, political, and economic progress in any given society, especially in the context of a globalized economy.

Lack of access to higher education deprives young women of an opportunity to optimize their selfrealization and full participation in the development process (Meena, 2007; Assie-Lumumba, 2007). Daddieh (2007) cites the weak foundation for female participation in tertiary education as a major culprit regarding women's under-representation in high level positions within or outside academia, or their concentration.

In today's very competitive world, the role of HEIs is being underpinned by the increasing dominance of an economic ideology (Wilton, 2007). According to Wilton (2007), HEIs have, therefore, increased the focus on the employability of their graduates and their transition into the labour market. The risk of this trend is that the institutions may shy away from their societal and moral obligations, which should include working towards gender equality.

Unfortunately, UN (2013:17) stated, "gender remains the most widespread and persistent facet of inequality, especially at the higher education level". According to Assie-Lumumba (2007), the history of women's engagement with the academy has been characterized by exclusion and inequality in almost all parts of the world ranging from the most developed nations such as Finland to the deserts of Negev in Israel and all the way down to the least developed ones, such as Ethiopia. In one of the most developed nations, Norway for instance, in terms of access, although some $60 \%$ of the university students were women (Soyland, et al., 2000:147), a panel of the gender advisors for higher education in the country found that women face challenges in terms of the conduciveness of the academic climate and promotion to high level portfolios.

In the midst of such challenges, HEIs have made a significant contribution to gender studies in the area of research and by producing gender experts, which in turn, have contributed to the improvements in gender mainstreaming in government development policies and plans, as well as the incorporation of the gender dimension in the development processes (Mlama, 2007). Mlama (2007), however, criticized the failure of African HEIs to seize the leadership in educational reforms from a gender perspective. Specifically, HEIs in many African countries have not taken sufficient measures to reform their institutions to be gender responsive, they do not have gender responsive policies and plans and still maintain gender non-responsive curricula. Such reforms would "thus produce experts in the form of economists, engineers, teachers, planners, scientists, doctors, and others who then go to lead professional development sectors without the necessary skills to mainstream gender in the development processes" (Mlama, 2007). 


\section{Research Methodology}

\subsection{Research Approach}

The nature of the objectives sought to be achieved and the problems to be investigated in this study dictates the use of both quantitative and qualitative approach. On the one hand, quantitative data is required to understand the current status of female in the University. On the other hand, qualitative data is required to assess the extent to which available policies are being utilized by the implementers. The study was also involved exploration and analysis of peoples' attitude, perceptions and understanding about the issue of mainstreaming gender equality and empowerment of women. Using mixed approach help to minimize the weakness of single approach and ensure the validity of gathered data. Moreover, using combination of qualitative and quantitative approach helps for the purpose of gathering extensive data from various sources.

\subsection{Design of the Study}

This study fits into the descriptive study design. Descriptive research provides an accurate account of characteristics of a particular individual, event or a group in real-life situations (Polit \& Humger, 1999). Therefore, this study is descriptive because gender mainstreaming policies and practices can be described in terms of conduciveness of the overall environment to gender mainstreaming, management and university community attitude, perceptions, and commitment towards gender mainstreaming in the University. Further, most of the ramifications of gender policies and practices are real and described in a sense that they can be experienced and observed affecting different facets of life. The research also employed "interpretive research tradition"; research that uses interviews to help to understand the issue in greater depth (UNISA, 2009). The qualitative interview is one of the major tools adopted in this research to collect data from purposely selected respondents and use triangulation in data sets and comparison of responses.

\subsection{Sampling Design and Methods}

A research study should aim to gather data from a sample that is representative of the whole population (Babbie \& Mouton, 2001; Bartlett, et al., 2001). The total size of the University is too large to consider as a whole. Accordingly, the population under study is divided into three strata: academic staff, students and administrative staff. Academic staff and students were addressed through questionnaires while administrative staffs were addressed through interview. For the purpose of administering the attitude survey questionnaires, among the students, only regular and undergraduate ones are targeted as sampling elements, because the extension and postgraduate programme students are not easy to reach owing the academic schedule. Besides, the regular students represent the lion's share in terms of number, as well as being the central focus of major development policies and practices. The other major category of target groups comprises the full time, active academic staffs of the University. Non-active academic staffs are left out for reasons similar to those non-regular students.

Three scenarios were considered in order to determine the optimal level of the sample size which could represent the target population in both a scientifically desirable as well as operationally feasible manner. The variable factor in the three scenarios presented below is the margin of error for the given confidence level of $95 \%$.

Table 3.1: Scenario analysis to determine sample size

Scenario I, margin of error 0.05

\begin{tabular}{|c|c|c|c|c|c|c|}
\hline $\begin{array}{l}\text { Population } \\
\text { category }\end{array}$ & $\begin{array}{l}\text { Target } \\
\text { population }\end{array}$ & $\begin{array}{l}\mathrm{Z}=\mathrm{Z} \text { value } \\
\text { (e.g. } \quad 1.96 \\
\text { for } 95 \% \\
\text { confidence } \\
\text { interval }\end{array}$ & $\begin{array}{l}\mathrm{P}=\text { Percentage } \\
\text { of picking } \\
\text { choice }\end{array}$ & $\begin{array}{l}\text { Margin of } \\
\text { error }\end{array}$ & $\begin{array}{l}\text { Sample size for } \\
\text { undefined } \\
\text { population size }\end{array}$ & $\begin{array}{l}\text { Final } \\
\text { corrected } \\
\text { sample size } \\
\text { for target } \\
\text { population }\end{array}$ \\
\hline Academic Staff & 857 & 1.96 & 0.5 & 0.05 & 384 & 265 \\
\hline Students & 11,262 & 1.96 & 0.5 & 0.05 & 384 & 371 \\
\hline Total & 12,119 & & & & & 636 \\
\hline
\end{tabular}


Scenario II, margin of error 0.07

\begin{tabular}{|c|c|c|c|c|c|c|}
\hline $\begin{array}{l}\text { Population } \\
\text { category }\end{array}$ & $\begin{array}{l}\text { Target } \\
\text { population }\end{array}$ & $\begin{array}{l}Z=Z \text { value } \\
\text { (e.g. } \quad 1.96 \\
\text { for } \quad 95 \% \\
\text { confidence } \\
\text { interval }\end{array}$ & $\begin{array}{l}\mathrm{P}=\text { Percentage } \\
\text { of picking } \\
\text { choice }\end{array}$ & $\begin{array}{l}\text { Margin of } \\
\text { error }\end{array}$ & $\begin{array}{l}\text { Sample size for } \\
\text { undefined } \\
\text { population size }\end{array}$ & $\begin{array}{l}\text { Final } \\
\text { corrected } \\
\text { sample size } \\
\text { for target } \\
\text { population }\end{array}$ \\
\hline Academic Staff & 857 & 1.96 & 0.5 & 0.07 & 196 & 160 \\
\hline Students & 11,262 & 1.96 & 0.5 & 0.07 & 196 & 193 \\
\hline Total & 12,119 & & & & & 353 \\
\hline
\end{tabular}

Scenario III, margin of error 0.10

\begin{tabular}{|c|c|c|c|c|c|c|}
\hline $\begin{array}{l}\text { Population } \\
\text { category }\end{array}$ & $\begin{array}{l}\text { Target } \\
\text { population }\end{array}$ & $\begin{array}{l}Z=Z \text { value } \\
\text { (e.g. } \quad 1.96 \\
\text { for } \quad 95 \% \\
\text { confidence } \\
\text { interval }\end{array}$ & $\begin{array}{l}\mathrm{P}=\text { Percentage } \\
\text { of picking } \\
\text { choice }\end{array}$ & $\begin{array}{l}\text { Margin of } \\
\text { error }\end{array}$ & $\begin{array}{l}\text { Sample size for } \\
\text { undefined } \\
\text { population size }\end{array}$ & $\begin{array}{l}\text { Final } \\
\text { corrected } \\
\text { sample size } \\
\text { for target } \\
\text { population }\end{array}$ \\
\hline Academic Staff & 857 & 1.96 & 0.5 & 0.10 & 96 & 86 \\
\hline Students & 11,262 & 1.96 & 0.5 & 0.10 & 96 & 94 \\
\hline Total & 12,119 & & & & & 180 \\
\hline
\end{tabular}

Pros and cons of the sample size

Statistically the least desirable but operationally the easiest

The larger the sample size, the more confident one can be that the answers truly reflect the population. This premise favours scenario I as the most desirable, with margin of error of 0.05 . Operationally scenario III is the easiest to manage and the least costly in terms of resources. Nevertheless, the margin of error of 0.10 is so wide that it detracts from the credibility of the outcome. Although scenario I posed some operational challenges, the researcher utilized it for improving the representativeness of the sample size.

\subsection{Data Sources and Collection Instruments}

The researcher used both primary and secondary data sources and types to gather qualitative and quantitative data. Primary data was collected through formal interviews using pre-designed questions from purposely selected administrative staff of the University and gender experts while informal interactions and structured questionnaires were used to gather data from students and academic staff. Document review was made in order to augment evidence from the primary sources. In addition, other secondary data were collected through review of relevant literatures from possible sources and formats, including books, articles and other related research documents.

\subsection{Method of Data Presentation and Analysis}

The data gathered was coded and entered into the computer software known as Statistical Package for Social Science (SPSS). The result of the SPSS analysis is summarized and presented in a form of table, bar-graphs, and pie-chart. In addition to these, qualitative data gathered from the interviews and document review is thematically presented and discussed thoroughly using descriptive analysis method.

\section{Results and Discussion}

\subsection{The University's Policy Environment}

This section reviews the conduciveness of the policy environment to address gender issues. It also explores how the policy environment is perceived by the stakeholders and how it is being effectively utilized. To this end, in addition to the relevant constitutional and national educational policy provisions, the revised Senate Legislation is reviewed. The review of the legislation from gender perspective demonstrates some degree of gender sensitivity.

For instance, article 5 of the legislation clearly states that the Director of Gender Office is a voting member of the Senate. Article 57 articulates the University's policy on affirmative action. It reads: “...the Senate or the President may issue guideline on special admission criteria that would enable disadvantaged group [including female students] to enroll in the programmes of the University..." (DU, 2013:59). Auxiliary article 63 mentions that the academic staff member should treat his or her students equally, irrespective of age, sex, nationality, or personal bias. The legislation also made it clear that failure to do so is subjected to disciplinary measures including dismissal from the University. To a certain extent, recognition for gender representation in important entities of the University is also made under article 97 which concerns the composition of the Academic Commission established for each College or Institute. The Academic Commission, among other members, is supposed to include two elected student representatives, one of whom shall be a female student. Article 112 
makes general provision for student organization, which includes the right to organize and promote interests of disadvantaged groups, female students, and students with disabilities, or students from emerging cultural communities.

Such gender-sensitive provisions are required in order to mainstream gender issues into different operations of the University's activities. As a result, the existing provisions should be considered as an important milestone in the process of ensuring gender equality in the University. As far as the implementation of such provision is concerned, a lot of effort is still needs to be in place to achieve the required outcome. For instance, even though female students have established Female Students Union as per the legislation, the union is currently suffering from financial constraints as well as lack technical support from University's management. It is important to understand that the establishment of Female Students Union is just a means to achieve the goal i.e. bringing gender equality. Therefore, the entire community of the University including top management is expected to contribute their part to achieve the intended objective.

From the extensive interview carried out with the key informants, the researcher come to understand that although the University is yet to compile a fully-fledged Gender Policy, others such as National Education Policy, the National Policy on Women, the Senate Legislation and other policy and strategy documents touch upon some aspects of gender issues such as availing opportunities equally and the empowerment of women. Questionnaire was administered on this specific point for the University academic staff; the result revealed that slightly more than one in two $(53 \%$ or $18 / 34)$ of the female academic staff that participated to responding to the questionnaire believed that Dilla University has some sort of policy related to gender. Out of the male academic staff that participated in responding to the questionnaire, slight more than two in five $(41.5 \%$ or $83 / 202)$ believed that the University has some sort of policy related to gender. This result indicates that there is a low level of awareness concerning the existence of any gender policy, particularly among the male academic staff. Among those who believed that there was a gender policy, slightly more than four in five $(83.3 \%$ or $15 / 16)$ of female academic staff and three in four $(73.5 \%$ or $61 / 83)$ of male academic staff believed that the policy affirms a commitment to gender equity. From the survey, one can understand that there is a positive attitude which the University could use when it enacts and implements a gender policy. On the other hand, the level of awareness about the gender related policy provisions is strikingly low among the student community. Out of the students that participated in responding to the questionnaire, sight more than three in five $(65 \%$ or $79 / 122)$ of female and seven in ten $(71 \%$ or $155 / 218)$ of male respondents responded that there was no gender policy or that they did not know if there was one after all.

The President of the University argued that "the University believes that the integration of gender equity in programmes and projects is mandated". According to him, "this is manifested by way of affording priority to women or girls whenever opportunities are available". For instance, whenever there are scholarships and internal vacant positions, one of the criterions for evaluation is sex. He believes that such measures by the University encourage their participation and ultimately contributes towards bridging the gender gaps. He further contended that the policy environment in the University is conducive to gender mainstreaming, and further stated that gender mainstreaming is taken care of in the new reform the University is currently undertaking. Unfortunately, the researcher was not afforded an opportunity to ask a follow up questions regarding this owing to the busy schedule of the President. However, according to a number of reports and draft policy documents that emerged from the planning of the on-going reform and those that were available to the researcher, the issue of gender mainstreaming was not visible in any significant way. The issue of gender, as in the past, was blended with other socio-economic variables such as ethnicity and religion being non-discriminatory factors regarding access to and utilization of resources.

\subsection{Human Resources}

It is obvious that the success and failure of an institution is highly dependent upon effective and efficient utilization of resources such as human, material, financial and information resources. However, the human element is the most crucial of all resources for the survival and prosperity of an organization since the human element of an organization has a lot to contribute to institutions performance. In this section, for analytical convenience, the University's human resources are grouped into three main categories: students, academic staff, and administrative staff. The section attempts to address the extent to which the goal of gender equity has been met in various aspects of human resources management policies and practices. Gender disaggregated data was obtained to evaluate the composition of female and male students, academic and administrative staff over the period of five years.

\section{Students}

As Mingat, Tan and Tamayo (2003) stated, when it comes to students, "equity in educational opportunity influences the future distribution of income, wealth and status in society". This is mainly because most of educated women are afforded better opportunities to earn higher wages, participate actively in community life and engage in decision-making processes among others. Gender equity is served better if equality is achieved 
since equity is the outcome of equality (Leo-Rynie, 1999). The most commonly used gender equality indicator amongst many researchers is the Gender Parity Index (GPI). The "GPI is the ratio of female to male enrollment, graduation...etc. A GPI of 1 indicates perfect equality between male and females, while a GPI closer to zero indicates high disparity between the participation of females as compared to males. In a class of 100 students, if 50 are female, then the GPI is 1" (MoE, 2010:27).

Figure 4.1: Dilla University GPI for regular undergraduate students at enrollment (2008/09-2012/13)

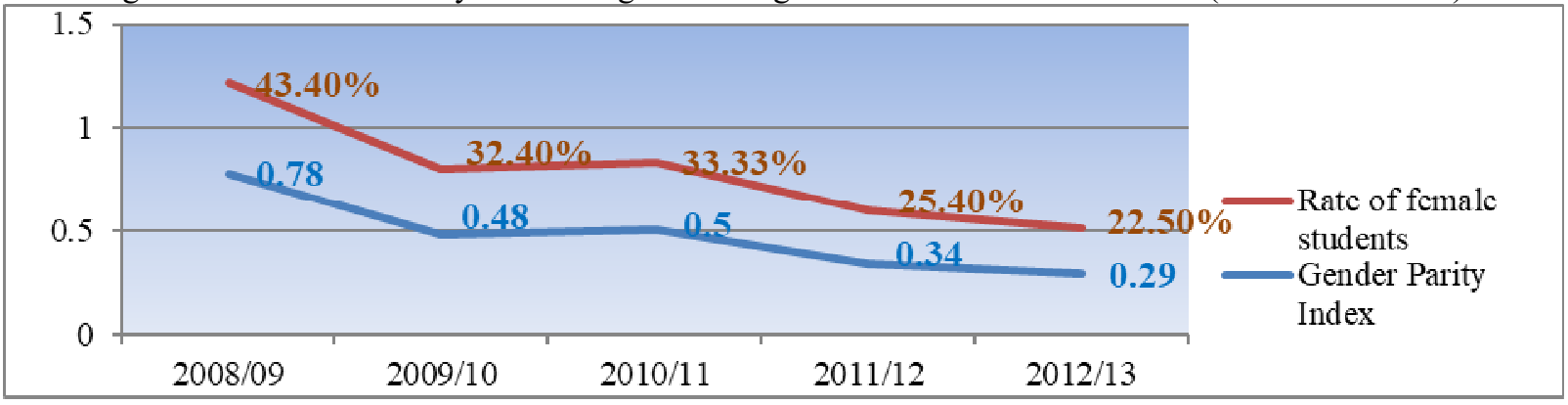

Source: Constructed by the researcher on the basis of data obtained from DU Registrar Office (2015)

As depicted in figure 4.1, there has not been any significant improvement in terms of achieving gender equity in the enrollment of regular undergraduate students through the years of 2008/09 to 2012/13. Instead, the Gender Parity Index for regular undergraduate student is showing continuous decline except in 2010/11 where the GPI increased to 0.50 from the previous year of 0.48 . The University registered the worst GPI in the academic year 2012/13, from the five years under review, which is 0.29 . This means that for every four male students, there was only one female counterpart during the same period. The enrollment rate of female undergraduate students was $43.4 \%$ of all students in 2008/09. In 2009/10 academic year the rate was slid back by $11 \%$. It indicated slight increment of $0.9 \%$ from the previous year in $2010 / 11$. In the next two academic years the rate was further slid back by $8.8 \%$ to be $22.5 \%$ in $2012 / 13$. Furthermore, in any one of the departments, female students did not constitute even half of the student population.

Figure 4.2: Dilla University GPI for regular postgraduate students at enrollment (2008/09-2012/13)

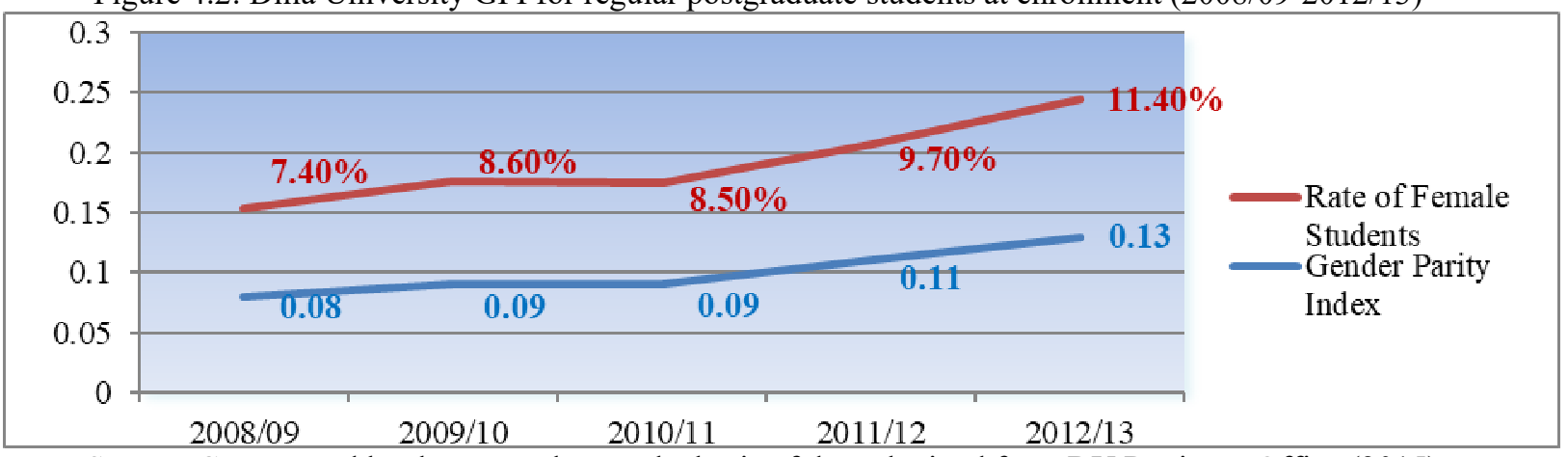

Source: Constructed by the researcher on the basis of data obtained from DU Registrar Office (2015)

The situation in postgraduate programmes was found to be worse as far as gender equality is concerned. During the five years under review, the maximum share of enrollment reached by the female students was $11.4 \%$ in $2012 / 13$. The average female students' share of the total postgraduate students over five years (2008/09$2012 / 13$ ) was only $9 \%$. In terms GPI, for every 1 female student, there had been 10 male students on average (see figure 4.2).

Figure 4.3: GPI differential between enrollment and graduation rates (undergraduate students)

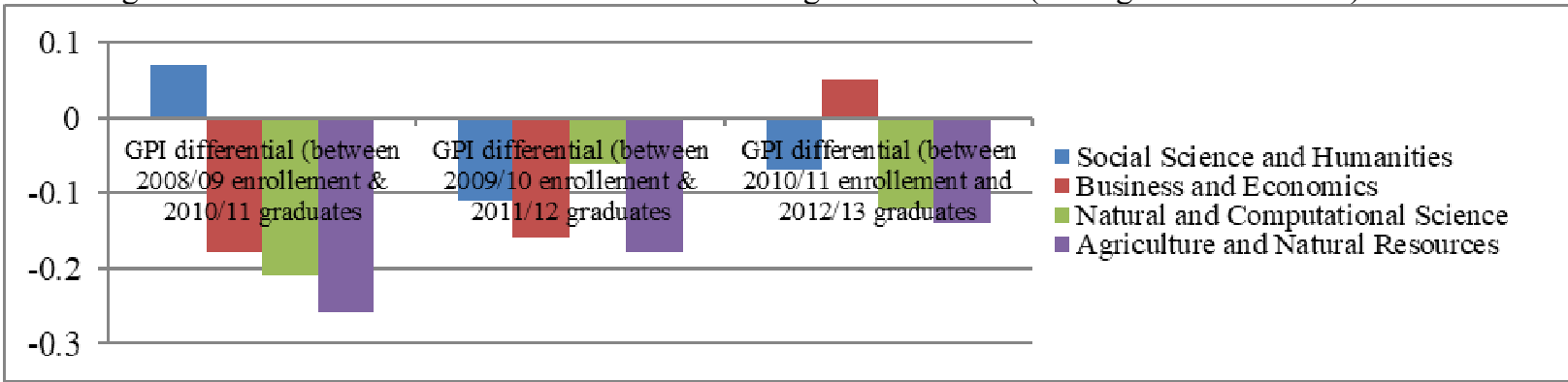

Source: Dilla University Registrar Office (2015) 
Figure 4.4: GPI differential between enrollment and graduation rates (graduate students)

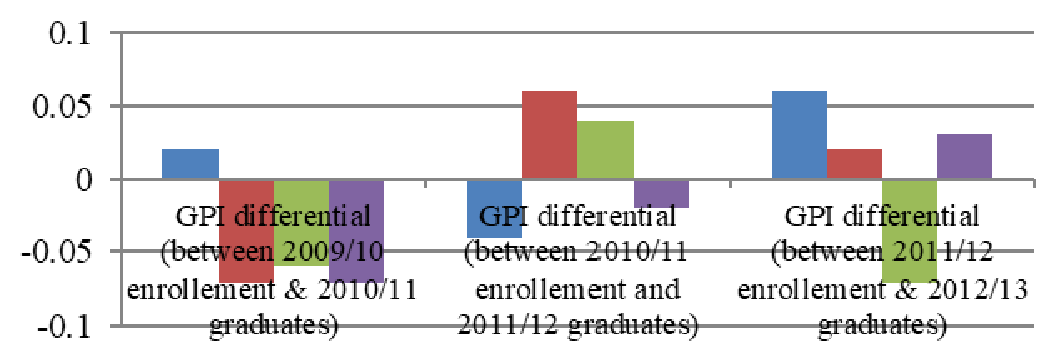

Social Science and Humanities

Business and Economics

natural and Computational Science

Source: Dilla University Registrar Office (2015)

Figure 4.3 and Figure 4.4 summarizes the GPI differential in terms of enrollment (access) vis-à-vis graduation (success) rates. The bar graphs in the negative axis represent the success rate of female students, which was less than that of male students. As the size of the graphs diminish, the GPI differential between the success and access rates approach zero. The GPI differential of zero is the ideal scenario with a zero attrition rate or a $100 \%$ success rate for both female and male students. As illustrated in Figure 4.3, the success rate of 2008/09 and 2010/11 female enrollees was less than that of their male counterparts except for the Social Science and Humanities and Business and Economics College respectively. While the entire success rate of 2009/10 female enrollees was less than that of their male counterparts in all Colleges considered for this analysis. From this one may conclude that the University didn't translate the existing polices into bridging the gender gaps in any significant way.

Coming to Figure 4.4, the average success rate of female graduate students was the lowest for 2009/10 enrollees, improved for 2010/11 enrollees and even more improved for 2011/12 enrollees, where female graduates recorded an unfavorable success rate only in Natural and Computational Science College. In this GPI differential, it should be noted that what is what is favorable for one sex is not favorable to the opposite sex. Therefore, the University needs to look deeply into the factors that contributed to the adverse attrition rates for both female and male students in all programmes.

\section{Academic Staff}

According to one of the key informant interviewee, the number of female academic staff in 2012/13 was very low as it comprised only $7.4 \%$ of the total academic staff of the University. For broader and deeper analysis of gender equality in this category of human resources, gender disaggregated data was obtained and analyzed.

Figure 4.5: Number of Dilla University academic staff by academic qualification

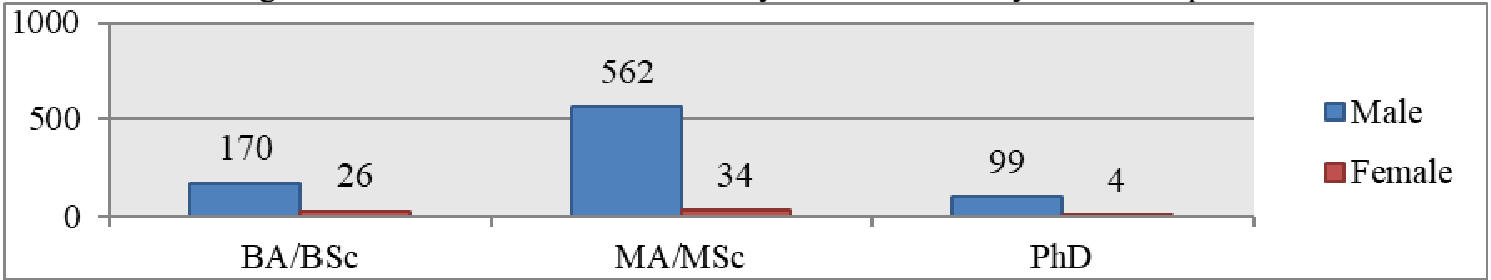

Source: Dilla University Human Resource Development and Management Office (2015)

In terms of qualification, as indicated in the previous chart, most of female academic staff held Master's Degree. The qualification profile of the female academic staff did not demonstrate any significant changes over the past five years when compared with their male counterparts. Using 2008/09 as a base year, female Master's Degree holders indicated an increment $13 \%$ while their male counterparts showed an increment of $37 \%$. The highest growth rate was registered among Bachelor Degree holders which showed an increment of $17 \%$. During the same year an increment was $31.6 \%$ for their male counterparts. The majority of the management team members who were contacted indicated that the most formidable challenge that the University faces in bringing about gender equality in the academic staff category is the shortage of qualified female intellectuals who are available and willing to pursue a teaching profession. They further emphasized that the University encourages female instructors to enhance their academic achievement by advancing their studies. This statement was not seconded by the findings from the survey, particularly by the female academic staff. Only sight less than two in five $(38 \%$ or $13 / 34)$ agreed that the management is committed to promoting female representation at senior levels of the University. On the other hand, among the male instructors, about three in five of the respondents $(59.9 \%$ or $121 / 202)$ agreed with the management's commitment in this regard. The academic staff survey participants were also asked if any proactive strategies were being implemented to recruit or promote women into senior positions. Of the female instructors, 55.9\% (19/34) and of the male instructors, 58.9\% (119/202) responded as 'not at all' or 'don't know'. This finding could imply that either there was communication breakdown between the management and the academic staff or that the management might need to reconsider the effectiveness of its staff recruitment and development schemes. 


\section{Administrative Staff}

Among the three categories of staff members, the administrative staff category could be regarded as either gender balanced or even inclined to being female dominated. As of February 2015, female employees constitute $55 \%$ of the total administrative staffs of the University. While this looks encouraging, further investigation revealed women made up the majority in the lowest administrative ranks and academic qualification (see figure 4.6). The researcher's intention to conduct a trend analysis of the administrative staff gender parity over a period of time did not materialize due to the unavailability of data. However, key informant interviewees disclosed that the staff composition and strength has been quite stable over years.

Figure 4.6: Number of Dilla University administrative staff by academic qualification

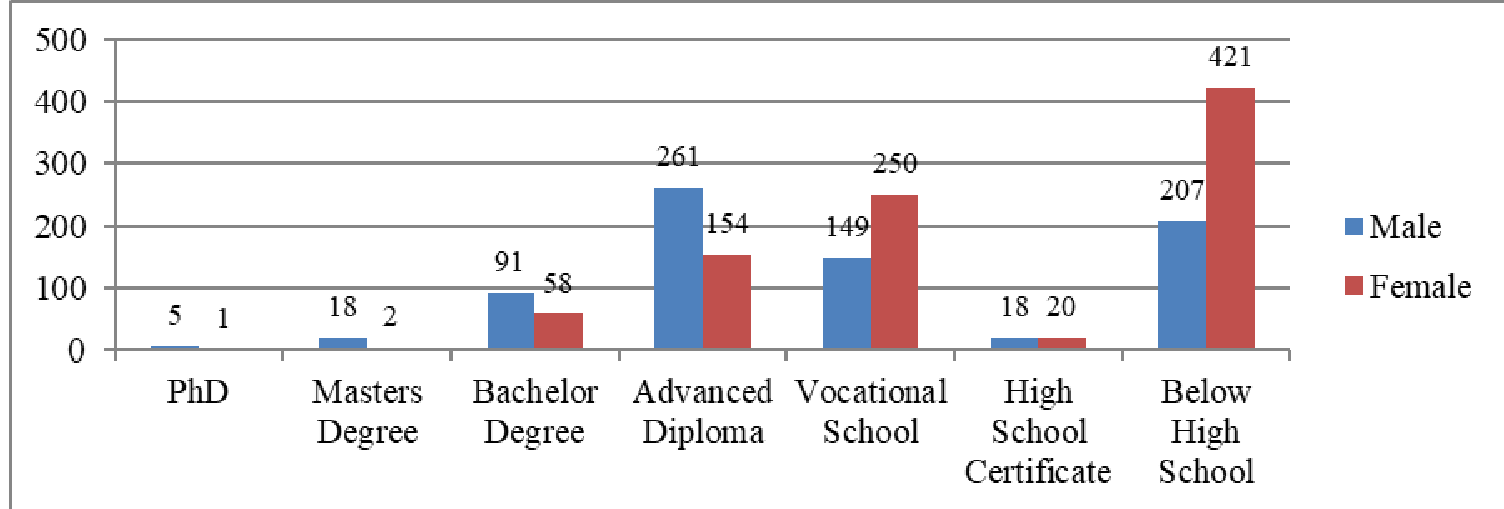

Source: Dilla University Human Resource Development and Management Office (2015)

According to the report obtained from the Gender Office of the University, the inventory of female who held a high level managerial portfolio indicates only two female Directors i.e. Gender Office and Office of Continuous and Distance Education. The University president expressed plan to increase this low level of female representation in high managerial position to 50\%. Again most of the interviewees including the President blame the lack of qualified and competent female professionals available to promote to higher managerial ranks to narrow the gender gaps at all levels in the institution. According to top management, to address this issue, the University has been building the capacity of existing female staff members and supporting them to develop themselves in all aspects. This top management claim was not supported by a significant majority of female academic staff respondents $(56 \%$ or $19 / 34)$ who responded that the management is not committed to promoting female representation at senior levels of the University while $52 \%(105 / 202)$ of males disagreed or expressed no opinion about it. Moreover, 91.2\% (31/34) of the female and 96.5\% (195/202) of male academic staff respondents agreed that meetings in the University tend to be dominated by male staff. The under representation of women in meetings where planning, evaluation and monitoring decisions are made places them at a disadvantaged position to make their voices heard as well as influences the outcome of the decisions.

\subsection{Financial Resources}

The researcher was unable to get hold of the existing financial policy to review in order to ascertain whether it makes any particular provision to support gender related issues. Instead, the researcher managed to obtain a copy of the draft financial policy which was prepared as part of institutional reform that the University has been undergoing. The financial draft manual did not clearly mentioned whether gender issues at all are one of the parameters against which resource allocation could be based or not.

The Gender Office informed the researcher that since 2010/11 the University had commenced allocating an overhead budget to run the Office. Furthermore, the Office received limited logistics and material support from Non-Governmental Organizations (NGOs). According to gender expert, the fund allocated is too small at times as compared with the required ones even to cover the basic office supplies. The expert further complained that due to a lack of funds, the annual orientation workshop planned for 2014's new students did not take place. Moreover, she informed the researcher that due to lack of funds, the Office was forced to narrow the scope of some training programs which were designed to create awareness among the University community about gender issues. The Vice President for Administration and Development also admitted that the resources committed by the University are limited. He, however, mentioned that the University is currently planning to increase the allocation of financial resources to Gender Office in order to increase the effectiveness of the Office to discharge its activities properly to bring the desired goal. The gender expert also stated that they plan to lobby with the University's top management and to mobilize resources from external sources so as to enable them to discharge their basic duties effectively. 


\subsection{Technical Expertise}

The researcher attempted to conduct an inventory of the staff responsible for gender related matters in the University. Moreover, the researcher also examines the actual effort in place to build in-house capacity to create gender-sensitive community in the institution. According to the Gender Office director, most of the employees that work in the Gender Office are not trained in gender related fields of study. Moreover, she acknowledged that the Office is understaffed and not well capacitated to realize its mission of "moving the University towards being an institution where both genders are fairly represented in all areas of the University's activities". The gender expert also affirmed that the University's level of technical expertise to design, implement and evaluate gender mainstreaming is 'not satisfactory'. Auxiliary, the Office is not sufficiently empowered to function effectively. The Gender Office director also clearly mentioned that gender issues are not sufficiently integrated into different operations of the University. The question was also posed to survey participants to determine whether they were aware that there was a staff responsible for gender integration in the different departments or programmes. The responses from the survey participants validated the argument of the Gender Office to a certain extent in that slight more than one in two $(53 \%$ or $8 / 34)$ of female and slight less than three in five $(56 \%$ or $113 / 202)$ of male academic staff respondents responded that they were either not aware or the gender issues are integrated into different operations of the University to a very limited extent.

Notwithstanding the constraints, according to the key informant interviewees, the Gender Office had accomplished activities such as arranging training for students in order to create awareness regarding HIV/AIDS, reproductive health, assertiveness, study methodologies, and sharing the experience of model students who excelled in academics. The Gender Office of the University also conducted management training for selected University staff. However, the staff members felt that the training which they had received was adequate only to a limited or moderate extent. It is obvious that if gender is to be mainstreamed at the University, a larger group of academic staff are supposed to have acquainted a basic skill with regards to gender planning and analysis. This precondition was not fulfilled satisfactorily as per the survey findings. Out of 34 female and 202 male academic staff, slight more than two in five $(41.2 \%)$ of females and sight less than seven in ten $(68.3 \%)$ of males responded that they had received any such training while slight less than three in ten $(29.4 \%)$ of females and slight less than two in ten $(17.8 \%)$ of males mentioned that they had received such training to a limited extent.

\subsection{Monitoring and Evaluation}

For the purpose of monitoring and evaluating the gender impact of a plan and programme, gender disaggregated data is crucial. In other words, in the absence of such basic data, it would be difficult for the University to monitor and evaluate its programmes and projects from a gender point of view. The University mostly follows the good practice of maintaining and disseminating gender disaggregated data on students, academic and administrative staff. The question now is whether the University uses this data to plan, monitor and evaluate the outcome of its programmes and projects from a gender perspective.

One key informant interviewee contended that the University monitors and evaluates the gender dimension of the implementation of the University's policy and operational interventions. According to him, the University applied gender as one of the selection parameters when filling the vacant positions in the University. On the other hand, the Gender Office disclosed that their respective Office was not involved in the monitoring and evaluation of the gender impact of the University's projects and programmes. The majority of male academic staff $(58.4 \%$ or $118 / 202)$ answered 'no' when asked if they knew whether or not the gender impact of these projects and programmes was monitored and evaluated, while a slim majority $(52.9 \%$ or $18 / 34)$ of the female academic staff expressed their awareness that the University evaluates and monitors the gender impact of its projects and programmes. These findings from various sources indicate that there is a disconnection between the management's argument and the perception of the staff members, especially among male academic staff, regarding the monitoring and evaluation of the gender impact of University's projects and programmes.

The survey participants prioritized which aspects of the University's projects or programmes contributed to better gender equity. As depicted in Figure 4.7, by order of priorities, the responses of female and male students were very similar. For both female and male students, 'access to resources' topped their priorities, followed by 'participation in decision making', 'access to training' and 'control over resources' in that order. For both female and male academic staff, 'access to training' headed the list. For female instructors, 'participation in decision making' came second; followed by 'access to resources'; whereas for male participants, the priority was the converse. 
Figure 4.7: Participants' prioritization of the University's programmes or projects contribution towards increased gender equity

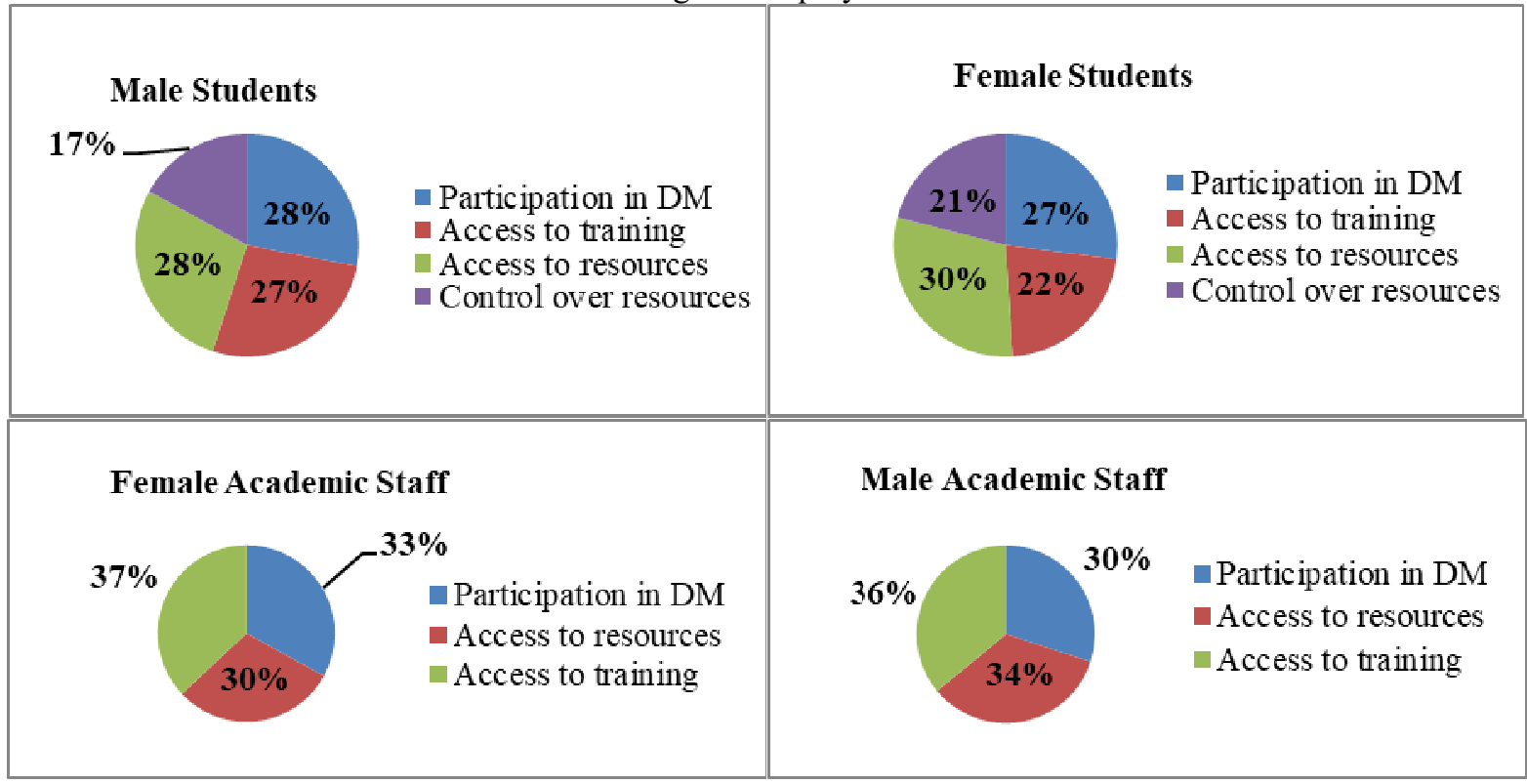

Source: Own Survey Result (2015)

The female and male academic staff respondents were not in harmony with regards to their understanding of what obstacles existed to incorporating gender analysis in programmes or projects planning and its implementation and evaluation in the University except for the fact that both placed 'insufficient training on gender' at the top of their list (see Figure 4.8). First of all female provide on average 3.5 obstacles while their male counterparts mentioned only 2.25 obstacles on average. This could demonstrate that female respondents are more concerned about the problems than their male counterparts. For female academic staff, 'insufficient financial resources' is the second factor followed by 'insufficient support from senior management' of the University. Despite their low numbers in academia, female academic staff respondents did not hesitate to place 'staff size' as the least likely factor that could prevent the University from integrating gender into its programmes and projects. For male academics, the second problem hindering the gender factor from being integrated into the University's system is 'office culture or environment' followed by 'insufficient financial resources'. 'Insufficient support from senior management' and 'low organizational priority for gender issues' were placed equally voted for by the male academic staff as being the least of all the given obstacles. Generally, the fact that female academic staff provided more obstacle than the male one could hint that not only men and women perceived the problems differently but also that women believed that there are more obstacles than men do.

Figure 4.8: Factors preventing the University from integrating gender into its programmes and projects

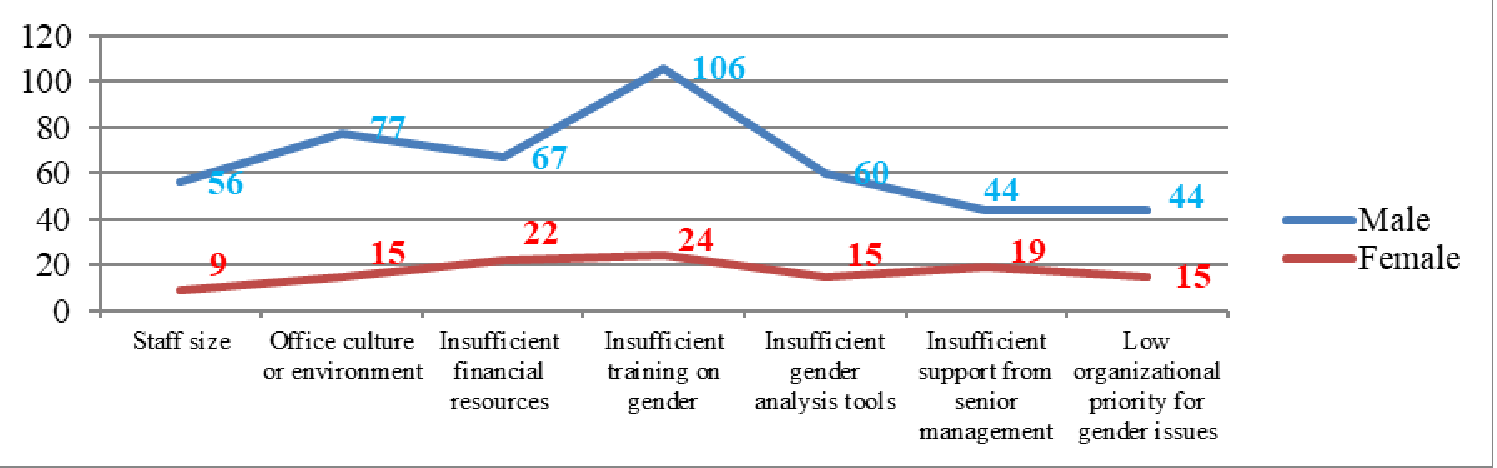

Source: Own Survey Result (2015)

\subsection{Organizational Culture, Perceptions and Attitudes}

Members of the academia, despite their exposure to higher learning, are not totally immune to backward cultural beliefs, biases and prejudices. Culture plays a vital role, for better or worse, in shaping the perceptions and attitudes of people towards a range of issues, including gender. As discussed, the concept of gender refers to the socially and culturally orchestrated assignment of roles and expectations as to how females and males behave in 
a given environment. For this reason, culture, perception and attitude play a paramount role in shaping the gender relations between men and women.

In the opinion of the key informants, the attitude of the University's community towards gender is not totally different from that of the larger community as the result of cultural influence. However, they believed that it is showing progress since the establishment of the Gender Office. In the opinion of gender expert, the members of the academia possess the 'intellect to hide their true feeling' concerning such issues and can paint a positive image which may not reflect the reality. The president of the University agreed with the gender expert in that it is difficult to identify what the actual attitude of the whole University community is towards gender issues although it seemed to him that it is generally positive. From the outset, the survey participants confirmed that the perception is unique to each individual. Slight more than three in five $(61.5 \%$ or $21 / 34)$ of female academic staff respondents perceived that there is a gap between the ways in which men and women in the University view gender issues. On the other hand a slight more than one in two (51.5\% or 104/202) of male academic staff expressed their view that there is a gap between how men and women in the University view gender issues. Survey participants were also requested to assess their own as well as the attitudes of other members of the University regarding gender related issues.

Table 4.1: Academic staff perceptions on the gender fairness of various opportunities in DU

\begin{tabular}{|c|c|c|c|c|c|c|c|c|c|c|}
\hline \multirow[b]{2}{*}{$\ddot{\varpi}$} & \multirow[b]{2}{*}{ 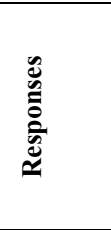 } & \multicolumn{9}{|c|}{ To what extent do you perceive the provision of the following opportunities to be gender-fair? } \\
\hline & & $\begin{array}{c}\text { Education \& } \\
\text { training } \\
\text { opportunit } \\
\text { ies }\end{array}$ & $\begin{array}{l}\text { Recognition } \\
\text { for good } \\
\text { work }\end{array}$ & $\begin{array}{c}\text { articipation } \\
\text { in } \\
\text { decision } \\
\text { making }\end{array}$ & $\begin{array}{c}\text { Freedom to } \\
\text { use one's } \\
\text { own } \\
\text { initiative }\end{array}$ & $\begin{array}{c}\text { Ppportunities } \\
\text { to exercise } \\
\text { leadership } \\
\text { in one's } \\
\text { workgroup }\end{array}$ & $\begin{array}{c}\text { Ppportunities } \\
\text { to exercise } \\
\text { leadership } \\
\text { within the } \\
\text { University }\end{array}$ & $\begin{array}{c}\text { Authority } \\
\text { over } \\
\text { resources }\end{array}$ & $\begin{array}{c}\text { On the job } \\
\text { challenges } \\
\text { for which } \\
\text { one has } \\
\text { responsibil } \\
\text { ity }\end{array}$ & $\begin{array}{c}\text { Career } \\
\text { developm } \\
\text { ent }\end{array}$ \\
\hline \multirow{4}{*}{ 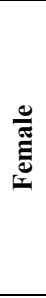 } & $\begin{array}{l}\text { Women } \\
\text { mainly }\end{array}$ & $1(2.9 \%)$ & $4(11.8 \%)$ & $0(0 \%)$ & $0(0 \%)$ & $3(8.8 \%)$ & $4(11.8 \%)$ & $2(5.9 \%)$ & $5(14.7 \%)$ & $5(14.7 \%)$ \\
\hline & $\begin{array}{l}\text { Men } \\
\text { mainly }\end{array}$ & $6(16.7 \%)$ & $9(26.5 \%)$ & $8(23.5 \%)$ & $3(8.8 \%)$ & $8(23.5 \%)$ & $14(41.1 \%)$ & $7(20.6 \%)$ & $5(14.7 \%)$ & $4(11.8 \%)$ \\
\hline & $\begin{array}{l}\text { Women } \\
\text { and } \\
\text { men } \\
\text { equally }\end{array}$ & $27(79.4 \%)$ & $21(61.7 \%)$ & $26(76.5 \%)$ & $31(91.2 \%)$ & $23(67.7 \%)$ & $16(47.1 \%)$ & $25(73.5 \%)$ & $24(70.6 \%)$ & $25(73.5 \%)$ \\
\hline & Total & $34(100 \%)$ & $34(100 \%)$ & $34(100 \%)$ & $34(100 \%)$ & $34(100 \%)$ & $34(100 \%)$ & $34(100 \%)$ & \begin{tabular}{|l|}
$34(100 \%)$ \\
\end{tabular} & $34(100 \%)$ \\
\hline \multirow{4}{*}{$\frac{0}{\tilde{x}}$} & $\begin{array}{c}\text { Women } \\
\text { mainly }\end{array}$ & $15(7.4 \%)$ & $17(8.4 \%)$ & $11(5.4 \%)$ & $13(6.4 \%)$ & $11(5.4 \%)$ & $10(5.0 \%)$ & $19(9.4 \%)$ & $33(16.3 \%)$ & $28(13.8 \%)$ \\
\hline & $\begin{array}{l}\text { Men } \\
\text { mainly }\end{array}$ & $28(13.9 \%)$ & $23(11.4 \%)$ & $75(37.1 \%)$ & $46(22.8 \%)$ & $55(27.2 \%)$ & $58(28.7 \%)$ & $41(20.3 \%)$ & $18(8.9 \%)$ & $29(14.4 \%)$ \\
\hline & $\begin{array}{l}\text { Women } \\
\text { and } \\
\text { men } \\
\text { equally }\end{array}$ & $159(78.7 \%)$ & $162(80.2 \%)$ & $116(57.5 \%)$ & $43(70.8 \%)$ & $136(67.3 \%)$ & $134(66.3 \%)$ & $42(70.3 \%)$ & $151(74.8 \%)$ & $145(71.8 \%)$ \\
\hline & Total & $202(100 \%)$ & $202(100 \%)$ & $202(100 \%)$ & $202(100 \%)$ & $202(100 \%)$ & $202(100 \%)$ & $202(100 \%)$ & $202(100 \%)$ & $202(100 \%)$ \\
\hline
\end{tabular}

Source: Own Survey Result (2015)

The overall perception of the both female and male respondents among the academic staff (see Table 4.1) and students (see Table 4.2) indicates that the University is somewhat gender-fair in of availing opportunities for both women and men. However, a close look at Table 4.9 uncovers the finding that the respondents' perceptions do not necessarily tally with respect to the gender fairness of the specific opportunities offered by the University. As portrayed in Table 4.2, it is interesting to note, for instance, that what is perceived to be the most gender-fair opportunity to male students (i.e. access to up-to-date technology) is the least gender-fair for female students. Female students identified 'educational and training opportunities' as the most gender-fair while their male counterpart identified participation in decision-making as the least gender-fair opportunity (see Table 4.2). Female academic staff choose 'freedom to use one's own initiative' as the most gender-fair opportunities (by $91.5 \%$ or $31 / 34$ respondents) in the University while they identified 'opportunities to exercise leadership within the University' as the least gender-fair opportunity (by $47.1 \%$ or $16 / 34$ respondents). The male academic staff respondents perceived that 'recognition for good work' is the most gender-fair opportunity (by $80.2 \%$ or $162 / 202$ respondents) whereas 'participation in decision making' is identified as the least gender-fair opportunity within the University (by $57.5 \%$ or $116 / 202$ respondents). Generally, it can be concluded from Table 4.1 and Table 4.2 that participation in decision making is the least gender-fair opportunity in the University as compared with other opportunities. 
Table 4.2: Students perception on the gender fairness of various opportunities in DU

\begin{tabular}{|c|c|c|c|c|c|}
\hline \multirow[b]{2}{*}{ מ. } & \multirow[b]{2}{*}{ Responses } & \multicolumn{4}{|c|}{$\begin{array}{l}\text { To what extent do you perceive the provisions of the following opportunities } \\
\text { are gender-fair? }\end{array}$} \\
\hline & & $\begin{array}{ll}\text { Education } & \text { and } \\
\text { training } & \\
\text { opportunities } & \end{array}$ & $\begin{array}{l}\text { Participation in } \\
\text { decision making }\end{array}$ & $\begin{array}{ll}\begin{array}{l}\text { Freedom } \\
\text { one's }\end{array} & \text { own } \\
\text { initiatives } & \end{array}$ & $\begin{array}{l}\text { Up-to-date } \\
\text { technology }\end{array}$ \\
\hline \multirow{4}{*}{ 苋 } & Women mainly & $11(9.0 \%)$ & $21(17.2 \%)$ & $8(6.5 \%)$ & $3(2.5 \%)$ \\
\hline & Men mainly & $23(18.9 \%)$ & $22(18.0 \%)$ & $29(23.8 \%)$ & $50(41.0 \%)$ \\
\hline & Women \& men equally & $88(72.1 \%)$ & $79(64.8 \%)$ & $85(69.7 \%)$ & $69(56.5 \%)$ \\
\hline & Total & $122(100 \%)$ & $122(100 \%)$ & $122(100 \%)$ & $122(100 \%)$ \\
\hline \multirow{4}{*}{$\sum^{\frac{0}{\pi}}$} & Wome & $21(9.6 \%)$ & (0) & $13(6.0 \%)$ & $8(3.7 \%)$ \\
\hline & Men $m$ & $51(23.4 \%)$ & $67(30.7 \%)$ & $50(22.9 \%)$ & $32(14.7 \%)$ \\
\hline & Wome & $146(67.0 \%)$ & $140(64.2 \%)$ & $55(71.1 \%)$ & $178(81.6 \%)$ \\
\hline & Total & $218(100 \%)$ & $218(100 \%)$ & $218(100 \%)$ & $218(100 \%)$ \\
\hline
\end{tabular}

Source: Own Survey Result (2015)

The survey participants expressed their assessment whether the overall environment in the University has improved for women over the past two years or not. The responses were mixed among the various members of the University's community. A larger proportion of male academic staff participants $(63.9 \%$ or 129/202) thought that the environment for women has improved over the past two years than the female academic staff $(55.9 \%$ or 19/34) thought. The opposite perception was revealed among the student respondents. More female students $(50 \%$ or $61 / 122)$ than their male counterparts $(46.3 \%$ or $101 / 218)$ believed that the environment has improved for women over the last two years. The Gender Office indicates that the situation for women has shown some degree of improvement over the last two years.

As many interviewees agreed, the culture in the University is a reflection of the culture in the country because University students can be referred to as representatives of the diverse Ethiopian cultures by all accounts, as they come together from all corners of the country in the quest for higher learning. In a patriarchal society like Ethiopia, there are many parables and proverbs that are gender insensitive and often undermine the constructive role women play in political, economic and social aspects of the country. These stories and proverbs are not merely harsh words rather they are also the manifestation of the deprivation that the women of Ethiopia have been suffering.

The University students were requested to indicate whether the University encourages gender sensitive behavior, for example, in terms of language used and the jokes and comments made. The pattern of response from both female and male students was similar but not encouraging. Among the female students that participated in responding to the questionnaire, slight less than three in five $(57.4 \%$ or $70 / 122)$ responded as 'don't know' or 'not at all', while slight less than one in two (49.1\% or 107/218) of male students responded in a similar manner. Slight less than three in ten $(28 \%)$ of female student respondents and slight more than three in ten $(35 \%)$ of male student respondents answered that the University discourages such insensitive behavior to a limited extent.

The academic staffs were asked if the culture of the University places a higher value on the manner in which males tend to work than on that for females. To a varying degree, the respondents concurred with each other on this. Slight more than seven in ten $(70.6 \%$ or $24 / 34)$ of female academic staff respondents and one in two $(51.5 \%$ or $104 / 202)$ of male academic staff respondents agreed with the statement. This finding somehow confirms that even academia is not immune from the negative stereotypes against women that are rampant in the society.

The social environment, in which students, especially females, find themselves when they enter a higher learning facility, is totally different from the relatively closed and parent controlled environment. The University environment affords them opportunities as well as poses challenges. One of the pervasive challenges is sexual harassment and discrimination (Semela, 2006). Legal and administrative protection is critical if this problem is to be mitigated. The Senate legislation provides the code of conduct to guard students against such acts as sexual harassment, intimidation and bullying (DU, 2013). It is also mentioned under section 5.2.1 of Federal Civil Servants Proclamation that sexual harassment is a serious offence (FDRE, 2007). Furthermore, the attitude survey conducted by the researcher on this matter identified a significant gap in the way students and academic staff perceives the regulatory enforcement of gender sensitive behaviour and procedures to prevent and address sexual harassment. Only $26.5 \%$ (9/34) of female academic staff, $31.7 \%$ (64/202) of male academic staff, $17.2 \%$ (21/122) of female students, and $23.4 \%$ (51/218) of male students felt that the University had adequately reinforced gender sensitive behaviour to address and prevent sexual harassment. DU's Vice President for Academic Affairs and Research asserted that the University should work more on creating awareness, stimulate discussion among the stakeholders and take serious legal measures against offenders to address sexual 
harassment incidents in the institution.

For most of the survey participants $(91.2 \%$ or $31 / 34$ of female academic staff, $86.1 \%$ or $174 / 202$ of male academic staff, $87.7 \%$ or $107 / 122$ of female students and $83.9 \%$ or $183 / 218$ male students), gender issues were not taken and discussed very seriously at the University. Open discussion and constant engagement of the community members would be important and might prompt the management to regard gender issues as one of its main agendas. There was an almost common reaction from across the spectrum of survey participants that the University could do much more than it is currently doing to institutionalize gender equality. However, the statement was more strongly supported by the female respondents than the male respondents. Nonetheless, 97.1\% (33/34) of female academic staff respondents, 85.1\% (172/202) of male academic staff respondents, $84.4 \%(103 / 122)$ of female student survey participants and $74.3 \%(162 / 218)$ of the male counterparts agreed with this statement. Moreover, overwhelmingly, both the female $(95.5 \%$ or $117 / 122)$ and male $(90.4 \%$ or 197/218) student survey participants suggested that addressing gender issues should be one of the top priorities of the University. In conclusion, many respondents agreed that the overall attitude of the University's community towards gender issues is not totally immune from gender-related stereotypes and gender-based discrimination.

\section{Conclusion and Recommendation}

Higher education institutions (HEIs) are critical in transforming the national development agenda into reality. They produce tomorrow's politicians, academics, entrepreneurs, or civil rights advocates. HEIs are, therefore, the powerhouses and strategic entry points through which the required paradigm shift can be instilled and cultivated. Gendered HEIs breed generations which believe that accelerated and sustainable economic development can be achieved by ensuring gender equality and the empowerment of women who have been marginalized for as long as history document.

DU, as one of Ethiopian public HIE is positioned to directly and positively impact the development efforts of the country. Is DU putting any effort into addressing gender issues? The answer is 'yes', although to a limited extent. In many instances the study revealed that gaps between facts and opinions do exist. This was even more evident in the responses of the top management which sometimes contradicted the findings from the document review and the attitude surveys. The researcher observed that a limited degree of management conviction was manifested in some policy provisions, including the allocation of limited resources. This research, therefore, identified that the University have attempted to address some gender issues, but in a fragmented fashion. The notion that gender issues should be everyone's business does not seem to be more than just rhetoric. The institutions seem to be content with this limited scope of intervention in addressing gender issues.

The ultimate answer to the main research question as to whether DU has mainstreamed gender to contribute towards gender equality and women empowerment is, 'not yet'. In short, in spite of some commendable but limited efforts, the University lacks the level of commitment, understanding, capacity, and operational institutional framework which is necessary for proper gender mainstreaming. Thus, in order to promote and strengthen strong side and control the weaknesses, the following recommendations are provided by the researcher based on the findings of the study:

- The human resources policies have to be reviewed so as to render them gender responsive. This will send the strong message that good performance in gender is rewarded professionally and financially. The management should also closely monitor the gender balance targets, analyze the obstacles and take corrective action to nurture a gender sensitive culture.

- The management should lead by example by showing commitment to gender mainstreaming. The management must also make clear policy statements, and communicate their orientation that gender mainstreaming is the way forward in the policies and practices of the institution. The statement should be followed by detailed action plans, institutional targets with set timeframes, incentives and accountability. Such strategic orientations should be matched with commitment in terms of providing adequate human, financial and logistical resources for the implementation of gender mainstreaming.

- It is important to set up and sustain institutional framework for gender mainstreaming: The University have Gender Office but it suffers from a lack of resources, voice and capacity to effectively discharge its responsibility. The University should nonetheless build on this modest foundation and strengthen Gender Office's infrastructure in terms of mandate and resources.

- The study revealed the existence of major attitudinal gap. Hence, the University should organize and conduct continuous awareness creation trainings and workshops for the University community. A detailed gender mainstreaming toolkit should be prepared and disseminated to augment the training process.

The researcher firmly believes that, should the recommendations be implemented properly, the University will be in a much better position to contribute towards gender equality and the empowerment of women which have the potential to escape this nature-blessed country from sticky poverty situation by generating gender- 
sensitive knowledge and power.

\section{References}

AAU (Association of African Universities). 2006. A Toolkit for Mainstreaming Gender in Higher Education in Africa. African Universities House. Accra.

Alemayehu, H. 2010. Meles Confident Ethiopia will Meet MDG in Education. The Reporter, 27 February:5.

Almaz, E. 2003. Women in Faculties of Teacher Training Institutions in Ethiopia. UNESCO IICBA. Addis Ababa.

Asmaru Berihun, 2010. Overviews of Female Education in Ethiopia. Gender Management Process, Ministry of Education, The Federal Democratic Republic of Ethiopia, Addis Ababa.

Assie-Lumumba, N.T. 2007. Women and Higher Education in Africa: Reconceptualising Gender-based Human Capabilities and Upgrading Human Rights to Knowledge. Mansfield: CEPARRED.

Babbie, E, \& Mouton J. 2001. The Practice of Social Research. Cape Town: Oxford University Press.

Barton, C. 2005. Where to for Women's Movements and the MDGs? Edited by Caroline Sweetman. Oxford: Oxfam GB.

Brett, A. 1991. Why Gender is a Development Issue. London: Oxfam.

Brown, G., \& Irby, B. 2005). Increasing gender equity in educational leadership. Paper presented at the annual meeting of the American Educational Research Association, Montreal, Canada.

Burns, N. \& Grove, K.S. 2005. Practice of Nursing Research: Conduct, Critique, and Utilization. St. Louis, Missouri: Elsevier Saunders.

Clisby, S. 2005. Gender Mainstreaming or Just More Male-streaming? Experiences of Popular Participation in Bolivia. Lapaz.

Cornwall, A., E. Harrison and A. Whitehead (2007) 'Introduction: feminisms in development: contradictions, contestations and challenges', in A. Cornwall, E. Harrison and A. Whitehead (eds.) Feminisms in Development: contradictions, contestations and challenges, London: Zed Books, pp. 1-17.

Cornwall, A., Harrison, E., \& Whitehead, A. 2004. Introduction: Repositioning Feminisms in Gender and Development. Brighton: University of Sussex.

Daddieh, C.K. 2007. Asymmetric Relations and Other Gender Issues in the Ghanaian Higher Education, Edited by Assie-Lumumba. Mansfield: CEPARRED.

Diaw, C. 2010. Remaining Barriers to Women's and Girls' Access to and Participation in Education and Training. UN Commission on the Status of Women, Fifty-fourth session, March 1-12, New York.

DU (Dilla University). 2013. University-wide Strategic Plan of Dilla University. January. Dilla

FAWE (Forum for African Women Educationalists) 1995. Girls and African Education Research \& Action to Keep Girls in School . FAWE International House, Kenya.

FAWE-Ethiopia (Forum for African Women Educationalist). 2009. Gender Sensitivity of National Teacher Education Policy and Assessment of the Status of Female Teacher Trainees. BRANA International Consultancy. Addis Ababa.

FDRE (Federal Democratic Republic of Ethiopia). 1994. Educational and Training Policy. Birhanena Selam Printing Enterprise. Addis Ababa.

FDRE (Federal Democratic Republic of Ethiopia). 1995. Constitution of the Federal Democratic Republic of Ethiopia. Addis Ababa.

Glick, Peter.2008. Policy Impacts on Schooling Gender Gaps in Developing Countries: The Evidence and a Framework for Interpretation, Cornell University.

Grown, C. 2005. Answering the Sceptics: Achieving Gender Equality and the Millennium Development Goals. Rome: Society for International Development.

Grunberg, L. 1999. Access to Gender-sensitive Higher Education in Eastern and Central Europe: Reflections from the CEPES project on 'Good Practice in Promoting Gender Equality in Higher Education'. Higher Education in Europe 24(3).

Grunberg, L. 2001. Studies on Higher Education: Good Practice in Promoting Gender Equality in Higher Education in Central and Eastern Europe. Bucharest: UNESCO (United Nations Educational, Scientific and Cultural Organization).

Hayes, C. 2005. Out of the Margins: the MDGs though a CEDAW lens. Edited by C. Sweetman. Oxford: Oxfam GB

Heyzer, N. 2005. Making the Links: Women's Rights and Empowerment are Key to Achieving the Millennium Development Goals. Edited by C. Sweetman. Oxford: Oxfam GB.

Hunter, P. 2004. Survey Analysis. Centre for Survey Research and Analysis. University of Connecticut. Hartford.

Husu, L. 2000. Gender Discrimination in the Promised Land of Gender Equality. Higher Education in Europe 25(2).

ILO (International Labour Organisation). 2009. Global Employment Trends for Women. March. Geneva. 
Jaquette, J.S. \& Summerfield, G. editors, 2006: Women and Gender Equity in Development Theory and Practice. Institutions, Resources and Mobilization. Durham and London: Duke University Press.

Johnson, R. 2005. Not a Sufficient Condition: The Limited Relevance of the Gender MDG to Women's Progress. Edited by Caroline Sweetman. Oxford: Oxfam GB.

Kabeer, N. 2003. Gender Mainstreaming in Poverty Eradication and the Millennium Development Goals. New Gender Mainstreaming Series on Development Issues. A Handbook for Policy-makers and other Stakeholders. Ottawa: International Development Research Centre.

Kabeer, N. 2005. "Gender equality and women's empowerment: a critical analysis of the third Millennium Development Goal" Gender and Development 13(2). Reprinted in Gender and the Millennium Development Goals. Oxfam Focus on Gender, OXFAM, Oxford.

King, E. M. and M. A., Hills, 1993. Women's Education in Developing Countries: Barriers, Benefits and Policies. Baltimore: The Johns Hopkins University Press.

Klasen, S. 2002. The Impact of Gender Inequality in Education and Employment on Economic Growth in Developing Countries: Updates and Extensions. Ibero-America Institute for Economic Research Working Paper No. 175. Goettigen, Germany: University of Goettingen.

Klein, S.S., Kramarae, C., Richardson, B. 2007. Examining the Achievement of Gender Equity in and through Education. Edited by Susan S. Klein, et al. New Jersey: Lawrence Erlbaum.

Leo-Rhynie, E., Institute of Development and Labour Law, University of Cape Town, South Africa. 1999. Gender Mainstreaming in Education. A reference manual for governments and other stakeholders. London: Commonwealth Secretariat..

Mac-Gillivray, E.D., Beecher, H.J.M., Golden D. 2009. Legal Developments-Gender Issues Now, and Increasingly in the U.S. and EU Spotlight. Global Business and Organizational Excellence. Wilmington: Wiley

Mama, A. 2004. Demythologising Gender in Development: Feminist Studies in African Contexts. Brighton: University of Sussex.

Meena, R. 2007. Women's Participation in Higher Levels of Learning in Africa. Edited by Assie-Lumumba. Mansfield: CEPARRED.

Mingat, A., Tan, J.P., \& Tamayo, S. 2003. Tools for Education Policy Analysis. Washington DC: World Bank.

Mlama, P. 2007. The Significance of Higher Education in Gender and Educational Reforms in Africa: the FAWE Experience. Edited by Assie-Lumumba. Mansfield: CEPARRED.

MoE (Ministry of Education), 2012. Education Statistics Annual Abstract 2010-11, Ministry of Education, The Federal Democratic Republic of Ethiopia, Addis Ababa.

MoE (Ministry of Education). 2004. Five-year Strategic Framework for Enhancing Women's Participation in Tertiary Education in Ethiopia. September. Addis Ababa: Women's Affairs Department.

MoE (Ministry of Education). 2009. Education Statistics Annual Abstract 2000 E.C. /2007-08/. Education Sector Development Programme Planning and Policy Analysis Department. Addis Ababa.

MoE (Ministry of Education). 2013. Education Statistics Annual Abstract. Addis Ababa. Ethiopia.

MoFED \& UNCT (Ministry of Finance and Economic Development and United Nations Country Team). 2011. Millennium Development Goals Report: Challenges and Prospects for Ethiopia. Volume 1. Addis Ababa.

MoFED \& UNCT (Ministry of Finance and Economic Development and United Nations Country Team). 2012. Ethiopia MDGs Report 2012: Assessing Progress Towards the Millennium Development Goals. Addis Ababa.

MoFED (Ministry of Finance and Economic Development). 2005. Ethiopia: The Millennium Development Goals (MDGs) Needs Assessment Synthesis Report. Addis Ababa.

Mohammed, H. 2002. Enrolment and Academic Performance of Female Students in Higher Learning Institutions: A Case Study. IER Flambeau. Addis Ababa University Institute of Educational Research. Addis Ababa 9(2).

Molyneux, M, \& Razavi, S. 2005. Beijing Plus Ten: An Ambivalent Record on Gender Justice. The Hague: International Institute of Social Studies.

Morley, L. 2005. Sounds, Silences and Contradictions: Gender Equity in British Commonwealth Higher Education. Australian Feminist Studies 46(20).

Moser, C, \& Moser, A. 2005. Gender Mainstreaming since Beijing: a Review of Success and Limitations in International Institutions. Oxford: Oxfam GB.

Mouton, J, Marais, HC. 1998. Basic Concepts in the Methodology of the Social Sciences. HSRC Studies in Research Methodology. Pretoria: HSRC Press.

Mukhopadhyay, M. 2004. Mainstreaming Gender or 'Streaming' Gender Away: Feminists Marooned in the Development Business. Brighton: University of Sussex.

Müller U. 2000. Gender Equality Programmes in German Institutions of Higher Education-The North RhineWestphalia Case. Higher Education in Europe, 25(2).

National Committee for the Advancement of Women in Vietnam. 2004. Gender Mainstreaming Guidelines in 
National Policy Formulation and Implementation: Towards Gender Equality in Vietnam through GenderResponsive National Policy and Planning: Hanoi.

Neuhold, B. 2005. Focus on Human Rights and Gender Justice. Linking the Millennium Development Goals with the Convention on the Elimination of All Forms of Discrimination against Women and the Beijing Platform for Action. Policy dissertation for Beijing+10 and the MDG+5 reviews. Wien: Netzwerk Women in Development Europe (WIDE Austria).

New Internationalist. 2005. Missing the Millennium Development Goals. January/February.

Nicola Jones, Karen Moore, Eliana Villar-Marquez and Emma Broadbent, 2008. Painful Lessons: The Politics of Preventing Sexual Violence and Bullying at School. Overseas Development Institute. London, UK.

Noor, KBM. 2008. Case Study: A Strategic Research Methodology. American Journal of Applied Sciences Science Publications, Universiti Industri Selangor. Shah Alam 5 (11)

OECD (Organization for Economic Cooperation and Development). 2009. Gender Equality in Ethiopia. Social Institutions and Gender Index. http://genderindex.org/country/ethiopia Downloaded: 2013-07-26

Onwuegbuzie, A.J., \& Daniel, L.G. 2003. Typology of Analytical and Interpretational Errors in Quantitative and Qualitative Educational Research. Current Issues in Education. http://cie.ed.asu.edu/volume6/number2/. Downloaded 2013-04-24.

Painter, GR. 2004. Gender, the Millennium Development Goals, and Human Rights in the Context of the 2005 Review Processes. Report for the Gender and Development Network. Montreal.

Permanyer, I. 2008. On the Measurement of Gender Equality and Gender Related Development Levels. Journal of Human Development 9(1).

Pessate-Schubert, A. 2004. The Sky is the Limit: Higher Education, Gender and Empowerment in the Bedouin Community in the Negev in Israel. Compare, 34(3).

President Obama to Push Congress on Pay-fairness Bill. 2010. USA Today. http://usatoday.com. Downloaded: 2013-06-08

Randell, Shirley, K and Gergel, Diana, R, 2009. Education of Girls in Africa. Federation of University Women in Africa Conference held in July, 2009, Lagos, Nigeria.

Razavi, S. \& Miller, C. 1995. From WID to GAD: Conceptual Shifts in the Women and Development Discourse. Geneva: United Nations Research Institute for Social Development.

Rena, Ravinder, 2004. Gender Disparity in Education: An Eritrean Perspective. Department of Business and Economics, Eritrea Institute of Technology, Asmara.

Robson, C. 1993. Real World Research. Oxford. United Kingdom: Blackwell.

Schuler, D. 2006. The Uses and Misuses of the Gender-related Development Index and Gender Empowerment Measure: A Review of the Literature. Journal of Human Development 7(2). July.

Self, S., \& Grabowski R, 2009. Gender Development, Institutions, and Level of Economic Development. Review of Development Economics 13(2).

Semela, T. 2006. Higher Education Expansion and the Gender Question in Ethiopia: A Case Study of Women in a Public University. The Ethiopian Journal of Higher Education. Addis Ababa University Institute of Educational Research. Addis Ababa 3(1).

Soyland, A., Skarsbo, A., Amble, N., Chrisensen, L., \& Olnes, A. 2000. Strategies for Achieving Gender Equality in Higher Education and Research in Norway. Higher Education in Europe 25(2).

Stromquist, N.P. 2007. Gender Equity Education Globally: Handbook for Achieving Gender Equity through Education. Edited by Susan S. Klein, et al. New Jersey: Lawrence Erlbaum.

Tamirie, A. 2006. Trend Analysis of Female and Male Academic Achievements in Different Educational Level. College of Education. Addis Ababa University. Addis Ababa University Press.

Teferra, D \& Altbah P.H. 2004. African Higher Education: Challenges for the $21^{\text {st }}$ Century. Chestnut Hill, MA: Center for International Higher Education, Campion Hall, Boston College.

Tembon, M. 2008. Girls' Education in the 21st Century: Gender Equality, Empowerment, and Economic Growth. Washington: The World Bank.

Teshome, N.2003. A Study of How and Why the Gap in Education of Girls and Boys widened during ESDP I in the Southern Nations Nationalities and Peoples' Region. Addis Ababa University, Ethiopia.

Tiessen, R. 2007. Everywhere/Nowhere: Gender Mainstreaming in Development Agencies. Bloomfield: Kumarian Press.

Turquet, L, Watt, P, Sharman, T. 2007. Hit or Miss? Women's Rights and the Millennium Development Goals. London: ActionAid.

UN (United Nations). 2005a. Progress towards the Millennium Development Goals,1990-2005: Goal 3: Promote Gender Equality and Empower Women. New York: United Nations Department of Economic and Social Affairs (DESA).

UN (United Nations). 2005b. Achievements, Gaps and Challenges in Linking the Implementation of the Beijing Platform for Action and the Millennium Declaration and Millennium Development Goals. Report of the 
Expert Group Meeting, Baku, Azerbaijan 7-10, February. New York: Division for the Advancement of Women of the United Nations.

UN (United Nations). 2009. The Millennium Development Goals Report 2009. July. New York: United Nations Department of Economic and Social Affairs (DESA).

UNDP (United Nations Development Programme). 2009. Human Development Report. Overcoming Barriers: Human Mobility and Development. http://hdr.undp.org/reports. Downloaded: 2013-02-25.

UNECA (United Nations Economic Commission for Africa). 2007. Assessing Progress towards the Millennium Development Goals in Africa. March. Addis Ababa: African Centre for Gender and Social Development.

UNESCO (United Nations Educational, Scientific and Cultural Organization). 1997. Gender-sensitive Education Statistics and Indicators: a Practical Guide. July. Paris.

UNESCO (United Nations Educational, Scientific and Cultural Organization). 2003a. Resolutions adopted by UNESCO's General Conference in Favour of Gender Equality and the Advancement of Women and Girls (1948-2001). September. Paris.

UNESCO (United Nations Educational, Scientific and Cultural Organization). 2007. Education for All by 2015. Will We Make it? EFA Global Monitoring Report. Paris: Oxford University Press.

UNFPA (United Nations Populations Fund). 2008. Delivering on the Promise of Equality: UNFPA's Strategic Framework on Gender Mainstreaming \& Women's Empowerment 2008-2011. New York.

UNIFEM (United Nations Development Fund for Women). 2004. CEDAW, Beijing and MDGs: Pathway to Gender Equality. New York.

UNMP (United Nations UN Millennium Project). 2004. From Promises to Action: Recommendations for Gender Equality and the Empowerment of Women. Task Force on Education and Gender Equality. Interim Report. New York.

USA-IQPEP. 2012. Exploring Policy-Practice Gaps of Female Leadership in the Ethiopian Education System. BRANA International Consultancy. Addis Ababa.

Vandemoortele, J. 2002. Millennium Development Goals: Looking Beyond the Averages. Observer 233. August. Ipswich.

Verloo, M. 2007. Gender Mainstreaming in Education and Employment. Torino: European Training Foundation.

WAO (Women's Affairs Office), 2004. A National Report on Progress made in the Implementation of the Beijing Platform for Action (Beijing +10 ). Office of the Prime Minister of the Federal Democratic Republic of Ethiopia. Addis Ababa.

WB (World Bank), 2002. Integrating Gender into the World Bank's Work: A Strategy for Action. January. Washington DC.

WB (World Bank), 2003. Gender Equality \& the Millennium Development Goals. 3 April. Washington DC.

WB (World Bank), 2009. The Little Data Book on Gender. May. Washington DC.

Wondimu, H. 2003. African Higher Education: An International Reference Handbook. Edited by Teferra D. and Altbach P. G., Boston: Indiana University Press.

World Bank. 2011. World Development Report 2012: Gender Equality and Development. Washington, DC. 